\title{
A hydrogen generator coupled to a hydrogen heater for small scale portable applications
}

\author{
Dirk Hufschmidt ${ }^{1}$, Gisela M. Arzac ${ }^{1,2}$, Maria Carmen Jiménez de Haro ${ }^{1}$ and Asunción Fernández ${ }^{1, *}$ \\ ${ }^{1}$ Instituto de Ciencia de Materiales de Sevilla (CSIC-Univ. Sevilla), Avda. Américo Vespucio 49, 41092-Sevilla, Spain. \\ ${ }^{2}$ Departamento de Química Inorgánica, Facultad de Química, Universidad de Sevilla, C/Profesor García González 1, 41012-Sevilla, \\ Spain.
}

\begin{abstract}
This study aims to build and test a small scale portable device able to couple a hydrogen generation system (based on a $\mathrm{NaBH}_{4}$ solution as liquid $\mathrm{H}_{2}$ carrier) to a hydrogen heater (based on the exothermic catalytic combustion of the released $\mathrm{H}_{2}$ ). The hydrogen generating system is based on the hydrolysis of stabilized solutions of $\mathrm{NaBH}_{4}$ (fuel solutions) which are pumped into the hydrolysis reactor. The generated $\mathrm{H}_{2}$ feeds the catalytic combustor. Two catalysts have been developed for the $\mathrm{H}_{2}$ generation and the combustion reactions able to operate at room temperature without need of additional energy supply. For the $\mathrm{NaBH}_{4}$ hydrolysis a Co-B catalyst was supported on a perforated and surface treated stainless steel (SS316) home-made monolith. For the flameless $\mathrm{H}_{2}$ catalytic combustion a Pt catalyst was prepared on a commercial SiC foam. The device was automatized and tested for the on-demand production of heat at temperatures up to $100^{\circ} \mathrm{C}$. In steady state conditions the $\mathrm{NaBH}_{4}$ solution flow is controlling the $\mathrm{H}_{2}$ flux and therefore the heater temperature. Once the steady-state is reached the system responds in a few minutes to up and down temperature demands from 80 to $100{ }^{\circ} \mathrm{C}$. The catalysts have shown no deactivation during the tests carried out in several days.
\end{abstract}

\section{Introduction}

For the implementation of the "hydrogen economy", challenges related to its sustainable and low-cost production, transportation and storage are under continuous investigation [1-5]. The use of $\mathrm{NaBH}_{4},(\mathrm{SBH})$ solutions as liquid hydrogen carrier constitutes an attractive strategy for hydrogen storage [6-8]. Solid SBH is stable in dry air, can be stabilized in basic solutions and produces hydrogen through its hydrolysis reaction (Eq.1). The borate by-product is non-toxic, and must be extracted from the spent fuel for further regeneration $[9,10]$.

$$
\mathrm{NaBH}_{4}+2 \mathrm{H}_{2} \mathrm{O} \rightarrow 4 \mathrm{H}_{2}+2 \mathrm{NaBO}_{2}
$$

The potential of SBH solutions for $\mathrm{H}_{2}$ storage and release, coupled to PEM fuell cells for mobile or portable applications have been previously considered [11-14]. In this work we aim to couple a $\mathrm{H}_{2}$ generation system to a reactor for the direct production of heat (e.g. cookers and heaters) based on the catalytic hydrogen combustion (CHC, Eq.2).

$$
\mathrm{H}_{2}+1 / 2 \mathrm{O}_{2} \rightarrow \mathrm{H}_{2} \mathrm{O}
$$

The CHC is a key reaction in the "hydrogen economy" because it is safe, controllable and highly exothermic $\left(286 \mathrm{~kJ} \cdot \mathrm{mol}^{-1}\right)$ [15]. This reaction can be employed for heat production as well as for safety purposes for the elimination of undesired hydrogen [15-17]. The catalysts in this work have been selected to operate at room temperature for both $\mathrm{H}_{2}$ generation and combustion reactions and have been deposited on selected structured supports according to the reactors' requirements [18]. The design of the $\mathrm{H}_{2}$ generation and combustion reactors and the final controlled heater device are described herein, together with the operation tests.

\section{Catalysts and catalytic reactors}

\subsection{The $\mathrm{H}_{2}$ generation by $\mathrm{NaBH}_{4}$ hydrolysis}

Co-B materials are the most investigated cobalt based catalysts for the SBH hydrolysis reaction and have been prepared on a wide range of conditions in powder as well as in supported form [12-14,19-21]. As catalyst's structured support, a homemade cylindrical monolith was fabricated from commercially available perforated stainless steel (SS316) as shown in Fig.1a [13-14]. The SS support was calcined at $900^{\circ} \mathrm{C}$ to produce a well adhered oxide layer according to a previous work [13]. Fig.1c shows SEM (scanning electron microscopy) images of the monolith oxidized surface at two magnifications. The Co-B catalyst was deposited by successive cycles of alternated immersions of the support on $30 \% \mathrm{CoCl}_{2} \cdot 6 \mathrm{H}_{2} \mathrm{O}$ and stabilized $19 \% \mathrm{SBH}$ aqueous solutions [13]. Fig. 1b shows the monoliths after deposition of the Co-B catalyst. A cylindrical reactor

Corresponding author: asuncion@icmse.csic.es 
with a total volume of $11 \mathrm{~mL}$ (hydrolysis reactor in Fig.3) can be made of PMMA or stainless steel. Catalytic monoliths are placed inside the reactor where the hydrolysis reaction will start spontaneously upon contact of the SBH stabilized solution with the catalysts.

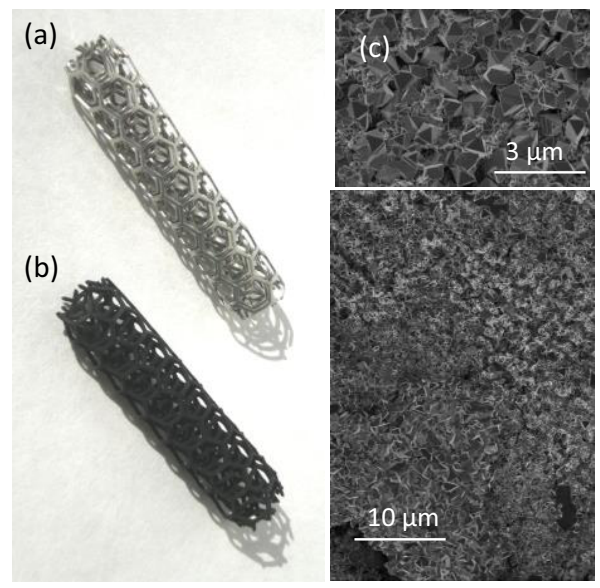

Fig.1. Stainless steel monoliths before (a) and after (b) deposition of the Co-B catalysts. (c) SEM images of monolith surface modified after thermal treatment.

\subsection{The catalytic $\mathrm{H}_{2}$ combustion}

For the flameless $\mathrm{H}_{2}$ catalytic combustion $\mathrm{Pt}$ and $\mathrm{Pd}$ are reported as the most active catalysts which permit to initiate the reaction without ignition even at room temperature [15, 22-23]. In this work a Pt deposited catalyst was prepared on commercial $\mathrm{SiC}$ foam by impregnation with an ethanolic solution of $\mathrm{H}_{2} \mathrm{PtCl}_{6}$ for a final Pt loading of $1.0 \mathrm{wt} \%$. The catalyst was dried in an oven and further calcined in static air at $400{ }^{\circ} \mathrm{C}$ during 4 h. Fig. 2 shows the commercial disc of alumina bonded $\mathrm{SiC}$ foam (from Lanik s.r.o., 80 pores per inch) before (a) and after (b) deposition of the Pt catalyst. Fig.2c shows SEM (scanning electron microscopy) surface images of the monolith $\mathrm{SiC}$ structured supports at two magnifications.

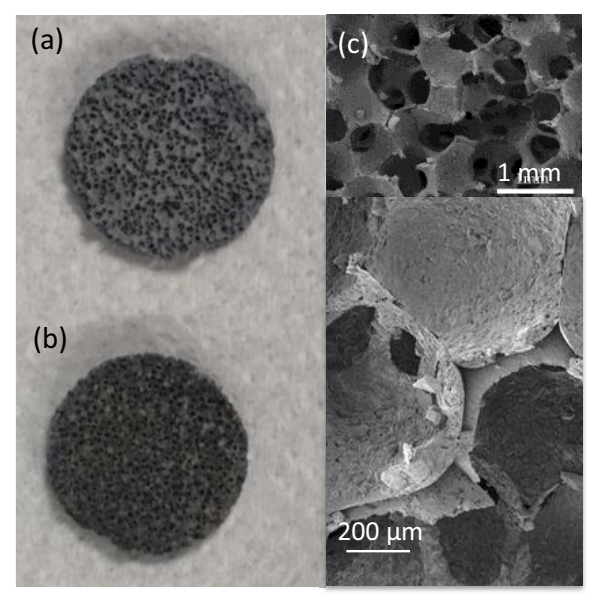

Fig.2. SiC monoliths before (a) and after (b) deposition of the Pt catalysts. (c) SEM images of the bare $\mathrm{SiC}$ foam surface.

The reactor (combustor in Fig.3) was made of stainless steel for $30 \mathrm{~mm}$ diameter and $5 \mathrm{~mm}$ thickness size of catalytic monoliths. $\mathrm{H}_{2}$ generated in the hydrolysis reactor will directly feed the combustor where the $\mathrm{CHC}$ reaction will start spontaneously in the presence of oxygen and the Pt catalyst.

\section{Controlled heater device for portable applications}

\subsection{The experimental design}

According to scheme in Fig.3 a prototype has been designed and constructed for a portable heater powered by $\mathrm{H}_{2}$. Stainless steel was used to fabricate the two reactors according to machining availability in the laboratory. The hydrolysis reactor and the residues tank could however be constructed with polymeric materials. The tank for the SBH fuel solution was made of PP polymer.

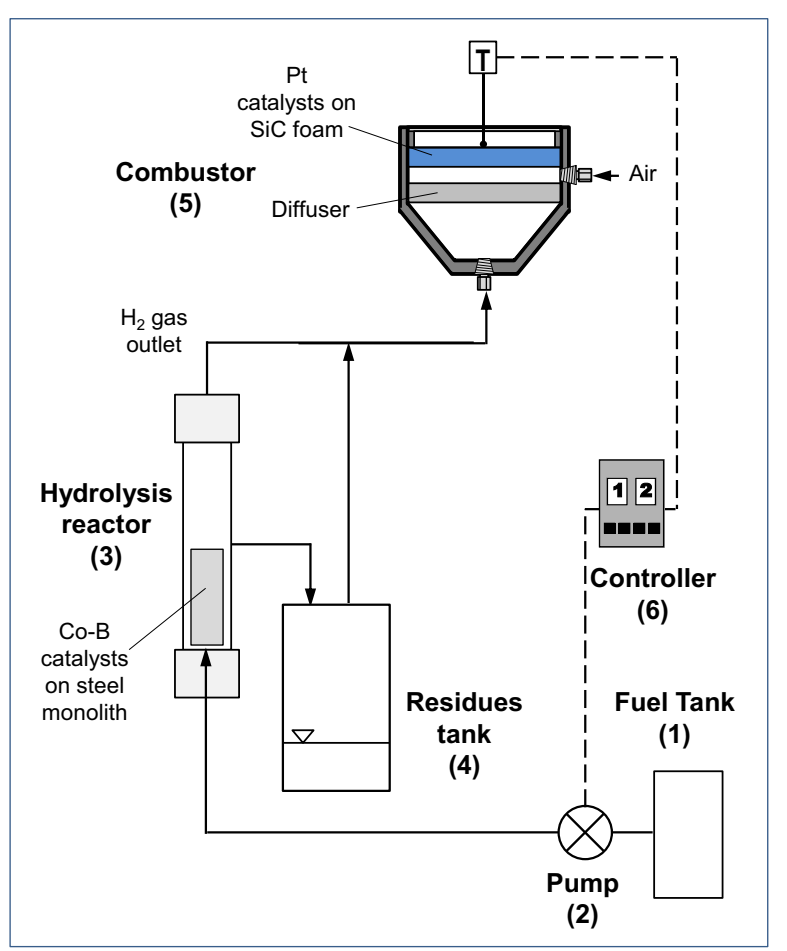

Fig.3. Scheme of the complete experimental design for a portable $\mathrm{H}_{2}$ heater: (1) Tank for the SBH fuel solution. (2) Micropump. (3) Hydrolysis reactor with catalytic monolith. (4) Tank for the borate residues solution. (5) $\mathrm{CHC}$ reactor with catalytic monolith. (6) Controller

The hydrolysis reactor consists of a tube of $105 \mathrm{~mm}$ long and $15 \mathrm{~mm}$ internal diameter. The reactor has three connections, the fuel inlet on the bottom, the waste outlet on the side and the gas outlet on the top. The waste outlet is connected to the waste tank (V ca. $300 \mathrm{~mL}$ ), which is also connected to the gas outlet line (pressure balance in the system). Inside the reactor is the home-developed stainless steel monolith with the CoB catalyst of $60 \mathrm{~mm}$ length and $12 \mathrm{~mm}$ diameter. The fuel enters the reactor from down, and in contact with the catalyst begins to evolve $\mathrm{H}_{2}$. The gas formed exits the reactor free from residues through the head of the reactor. At a height of 75 $\mathrm{mm}$ there is a connection (min. 1/8") for the elimination 
and separation of the reacted fuel to the waste tank. With this configuration the catalyst is wet during operation and the synergism between the high temperatures achieved and the continuous elimination of the spent fuel, prevent borates from crystallization on the surface of the $\mathrm{CoB}$, which could easily cause deactivation $[12,13]$. Fig.4 shows the experimental realization of the portable $\mathrm{H}_{2}$ generator which also includes a thermocouple for reaction temperature measurements. The selected micropump was from HNP Microsysteme with reference mzr2921.

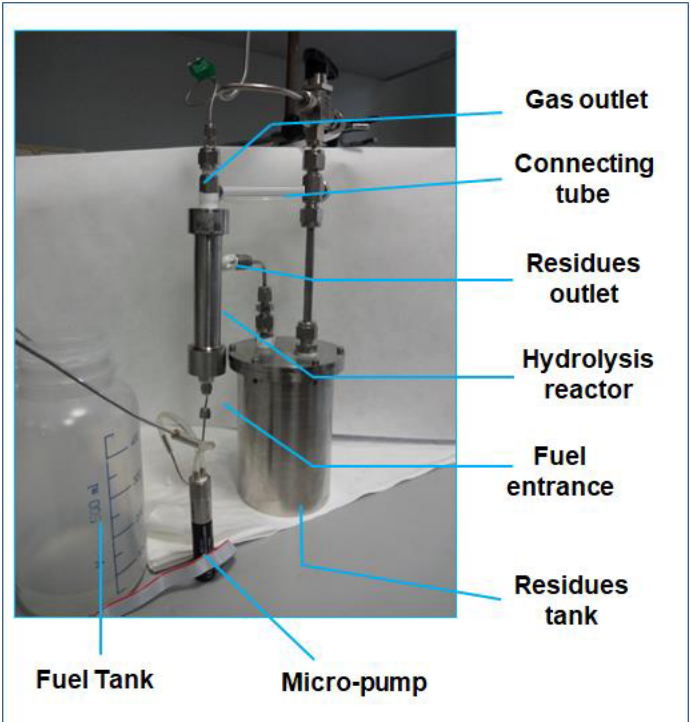

Fig. 4. Experimental realization of the portable $\mathrm{H}_{2}$ generator.

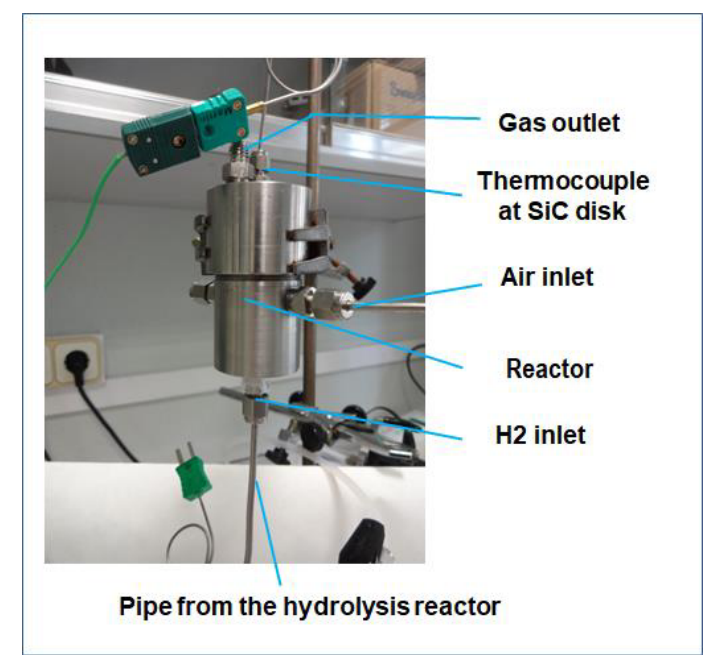

Fig. 5. Experimental realization of the $\mathrm{H}_{2}$ combustor.

The catalytic combustion reactor is connected to the hydrolysis reactor $\left(\mathrm{H}_{2}\right)$ and to the air supply from a compressor (for a final device a miniature air pump may be used). The reactor consists of a stainless steel body with an internal diameter of $30 \mathrm{~mm}$ and a height of 50 $\mathrm{mm}$. The conical bottom with the gas inlet is $20 \mathrm{~mm}$ high and is filled with quartz wool for free volume reduction. On top it is a disc ( $5 \mathrm{~mm}$ thick) of the bare porous $\mathrm{SiC}$ foam as a diffuser. Above it is a free space where the air inlet is placed and is mixed with the $\mathrm{H}_{2}$. In the upper part the porous $\mathrm{SiC}$ plate with the deposited catalyst is located. The heat resulting from catalytic combustion is measured with a K-type thermocouple, which is in contact with the center of the catalytic plate. The reactor can be used in the open mode (for the final portable device) or with a cap including a gas outlet for gas chromatographic (GC) analysis. Fig.5 shows the experimental realization of the portable $\mathrm{H}_{2}$ combustor.

\subsection{The operation tests}

With the objective of controlling the heater temperature by the fuel addition rate, tests were performed with the following conditions:

(i) $\mathrm{SBH}$ hydrolysis reaction: Fuel $\left(\mathrm{NaBH}_{4}\right)$ concentration 1-2 wt.\%. Fuel flow between $0.5-2 \mathrm{~mL} / \mathrm{min}$. In these conditions the maximum $\mathrm{H}_{2}$ production is $30 \mathrm{~mL} / \mathrm{min}$. Maximum usage time: determined by the capacity of the waste tank (ca. $3 \mathrm{~h}$ in this prototype).

(ii) Catalytic hydrogen combustion: Air flow 800 $\mathrm{mL} / \mathrm{min}$, fixed to ensure a concentration of $\mathrm{H}_{2}$ in air below 4 vol.\%. $\mathrm{H}_{2}$ flow up to $30 \mathrm{~mL} / \mathrm{min}$. $\mathrm{H}_{2}$ conversion (determined by GC) $>99 \%$
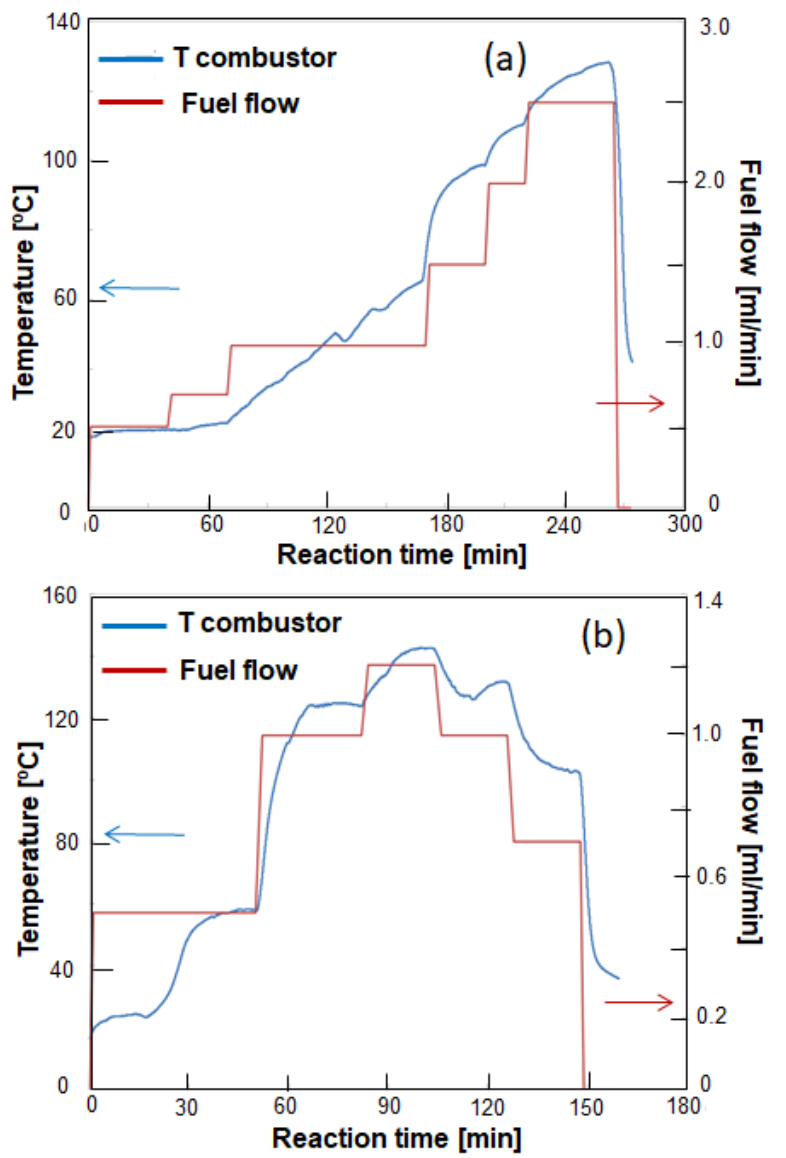

Fig. 6. Relationship (as a function of experiment time) between the combustor temperature and the SBH fuel solution flow which is feeding the $\mathrm{H} 2$ generator. (a) $1 \mathrm{wt} \% \mathrm{NaBH} 4$, (b) 2wt.\% NaBH4. 
First tests were devoted to determine the relationship between the fuel flow feeding the hydrolysis reactor and the temperature resulting in the combustor. Two SBH concentrations ( 1 and 2 wt.\%) were compared. Results are shown in Fig. $6 \mathrm{a}$ and $6 \mathrm{~b}$ respectively. In both cases it is observed an increase in temperature, due to the hydrogen combustion, with an increased fuel flow. The reason is that there is a correlation between the fuel addition and the hydrogen generation rates $[12,13]$. With the $1 \mathrm{wt} . \%$ fuel a maximum temperature of $128^{\circ} \mathrm{C}$ can be reached with $2.5 \mathrm{~mL} / \mathrm{min}$ flow and $100{ }^{\circ} \mathrm{C}$ is reached with $1.5 \mathrm{~mL} / \mathrm{min}$ fuel. Comparatively lower flows are needed and higher temperatures are reached for the $2 \mathrm{wt} \% \%$ fuel as expected [12-13]. With a $1.2 \mathrm{~mL} / \mathrm{min}$ flow, $142{ }^{\circ} \mathrm{C}$ can be reached while to achieve $100^{\circ} \mathrm{C}$ a flow of ca. 0.7 $\mathrm{mL} / \mathrm{min}$ of fuel was needed. For the range of around 100 ${ }^{\circ} \mathrm{C}$ the $1 \mathrm{wt} \% \mathrm{SBH}$ fuel was selected to test the application of an electronic control at these moderate temperatures.

Second tests were therefore done connecting the micropump to the electronic controller as shown in Fig. 3. The objective is to control the flow of the fuel in relation to the desired temperature of the combustor. Two set-point temperatures have been chosen, $100^{\circ} \mathrm{C}$ and $80^{\circ} \mathrm{C}$.

To avoid a long initial induction period, observed in preliminary experiment, a quantity of $2 \mathrm{~mL}$ of $19 \mathrm{wt} \%$ SBH fuel has been initially injected, resulting in the production of ca. $600 \mathrm{~mL}$ of $\mathrm{H}_{2}$. This will purge the complete system from air and will stablish a base $\mathrm{H}_{2}$ pressurization in the system. Once the combustor is at room temperature the experiments start. The set points temperatures given to the controller, along the experiment time, are indicated in red in Fig. 7.

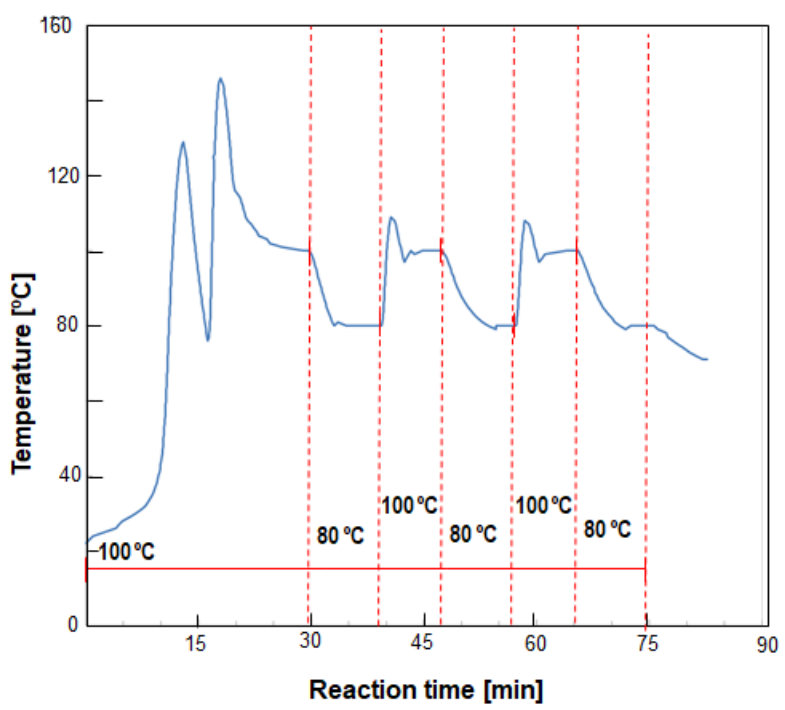

Fig. 7. Evolution of the $\mathrm{H}_{2}$ combustor temperature upon time as a response to the set-point temperatures given to the controller in an automatic mode operation

Despite the previous injection of the concentrated fuel to purge and pressurize the system, the combustor starts to heat up slowly what results in a high flow demand of fuel. Due to this, an intense temperature increase can be observed at the beginning of the experiment until the system finally stabilizes at the predetermined temperature of $100{ }^{\circ} \mathrm{C}$. This peak also results in high fuel consumption. Once in the range of this temperature, the system reaches the selected temperatures in a short time $(2-3$ min $)\left(80^{\circ} \mathrm{C}-100^{\circ} \mathrm{C}-80^{\circ} \mathrm{C}-100^{\circ} \mathrm{C}-80^{\circ} \mathrm{C}\right)$, demonstrating the regulation effectiveness of the controller system.

No deactivation of the catalysts has been observed, neither in this automated experiment, nor in the previous manual experiment.

\section{Conclusions}

In summary, in this work a small portable heater which operates at room temperature was designed and built. The system is based on coupling a hydrogen generator with a hydrogen combustor. The controlled addition of SBH in the form of stabilized solution (fuel solution) permits to generate hydrogen in a controlled rate to feed the combustor. In steady state conditions, the temperature of the combustor was tuned with the fuel addition rate, which was controlled with the micro-pump. The system operating in an automate mode, was able to respond fastly to the desired temperature from $80^{\circ} \mathrm{C}$ to $100^{\circ} \mathrm{C}$ and vice-versa. When the system is demanded to increase the temperature, the heating is slow, resulting in the increase of a fuel addition rate which produces a peak in the temperature of the combustor. On the contrary, the system responds more efficiently to a demand for decreasing temperature. The catalysts chosen for the hydrogen generator and the combustor demonstrated to be adequate to initiate the reactions with no extra energy supply and stable during each experiment and upon cycles. For a final mobile device the system requires the integration of a small battery (or fuel cell also fed by the $\mathrm{H}_{2}$ generator) to power the small controller and both fuel and air micro-pumps. The designed (SS monolith) and selected ( $\mathrm{SiC}$ disk) structured supports met the geometric requirements of each reactor and the necessary surface roughness for high catalyst anchorage.

In sum, the results presented herein constitute a proof of concept which can be adapted and scaled to different temperature demand. The operation time is limited by both the fuel addition and residues tanks which could be eventually replaced during operation.

\section{Acknowledgements}

Financial support is acknowledged from the Junta de Andalucía (grant PE2012-TEP862, EU co-financed by FEDER). This study was also supported by the Spanish Ministry of Science, Innovation and Universities and cofinanced by EU FEDER funds under grant RTI2018093871-B-100. The support of V. Gallardo and B. Sarmiento (Abengoa Hidrógeno) to the integration of the system electronic control is also acknowledged.

\section{References}

1. E.S. Hanley, J.P. Deane, B.P.Ó. Gallachoir, Int. Sustain. Energy Rev. 82, 3027 (2018) 
2. L. Shlapbach, A. Züttel, Nature 414, 353 (2001)

3. J. O. 'M. Bockris, Int. J. Hydrogen Energy 38, 2579 (2013)

4. P. Nikolaidis, A.Poullikkas, Renew. Sustain. Energy Rev. 67, 597 (2017)

5. T.S. Veras, T.S. Mozer, D.C. Rubin Messender dos Santos, A.S. Cesar, Int. J. Hydrog. Energy 42, 2018 (2017)

6. H. Jiang, S.K. Singh, J. Yan. X. Zhang, Q. Xu, ChemSusChem 3, 541 (2010)

7. P. Brack, S.E. Dann, K.G. Upul Wijayantha, Energy Sci Eng 3, 174 (2015)

8. U.B. Demirci, Energy Technol 6, 470 (2018)

9. D.M.F. Santos, CAC Sequeira, Int J Hydrogen Energy 35, 9851 (2010)

10. W. Chen, L.Z. Ouyang, J.W. Liu, X.D. Yao, H. Wang, Z.W. Liu et al. J. Power Sources 359, 400 (2017)

11. U.B. Demirci, O. Adkim, J. Andrieux, J. Hannauer, R. Chamoun, P. Miele, Fuel Cells 10, 335 (2010)

12. G.M. Arzac, A. Fernández, A. Justo, B. Sarmiento, M.A. Jiménez, M.M. Jimenez, Journal of Power Sources 196, 4388 (2011)

13. G.M. Arzac, D.Hufschmidt, M.C. Jiménez de Haro, A. Fernández, B. Sarmiento, M.A. Jiménez, M.M Jiménez, Int. J. Hydrogen Energy 37, 14373 (2012)

14. G.M. Arzac, D.Hufschmidt, E. Jiménez-Roca, A. Fernández, M.A. Jiménez et al. Process for the production of hydrogen through catalytic hydrolysis on a continuous reactor designed for this procedure. Spanish Patent application P201230221. Priority date 14-Feb-2012. Presented by Abengoa Hidrógeno S.A.

15. M. Haruta, H. Sano, Int. J. Hydrogen Energy 7, 737 (1982)

16. W. Choi, S. Kwon, H. D. Shin, Int. J. Hydrogen Energy 33, 2400 (2008)

17. C. Zhang, J. Zhang, J. Ma, Int. J. Hydrogen Energy 37, 12941 (2012)

18. A. Cybulski, J.A. Moulijn, Structured Catalysts and Reactors (CRC Press, $2^{\text {nd }}$ edition, 2005)

19. S.S. Muir, X. Yao, Int J. Hydrogen Energy 36, 5983 (2011) and references therein

20. U.B. Demirci, P.Miele 12, 14665 (2010) and references therein

21. G.M. Arzac, T.C. Rojas, A. Fernández, ChemCatChem 3, 1305 (2011)

22. F. Giarratano, G.M. Arzac, V. Godinho, D. Hufschmidt, M.C. Jiménez de Haro, O. Montes, A. Fernández, Appl. Catal. B: Environmental 235, 168 (2018)

23. A. Fernández, G.M. Arzac, U.F. Vogt, F. Hosoglu, A. Borgschulte, M.C. Jimenez, O. Montes, A. Züttel, Appl. Catal. B: Environmental 180, 336 (2016) 